\title{
Psychometric Examination of an Arabic Version of the State-Trait Anger Expression Inventory
}

Motohiro Nakajima, ${ }^{1}$ Ines Bouanene, ${ }^{2,3}$ Sana El-Mhamdi, ${ }^{2,3}$ Mohamed Soltani, ${ }^{2,3}$ Stephan Bongard, ${ }^{4}$ *Mustafa al'Absi ${ }^{1}$

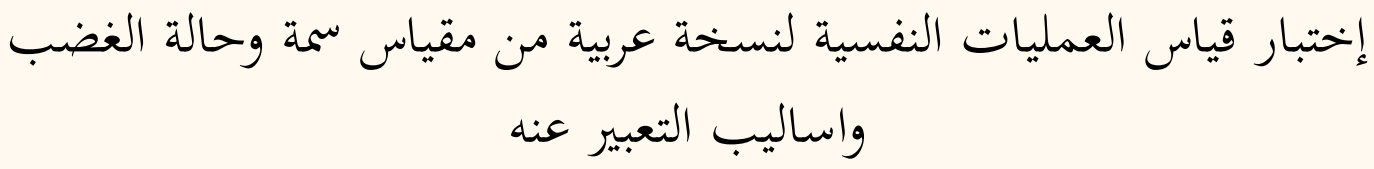

موتوهيرو ناكاجيما، إيناس بوعنان، سناء المحدي، محمد سلطاني، ستيفن بونجارد، مصطفى العبسي

ABSTRACT: Objectives: This study aimed to examine the psychometric properties of an Arabic version of the trait anger and anger expression scales of the State-Trait Anger Expression Inventory (STAXI). Methods: This study took place between April 2005 and August 2014. Adults in Yemen $(n=334)$ and Tunisia $(n=200)$ were recruited from university campuses and a smoking cessation clinic, respectively. The STAXI was translated into Arabic using backtranslation methods. An explanatory principal component analysis was conducted to explore the factor structure of the anger expression scale, utilising parallel analyses to determine the number of retained factors. Results: Good internal consistency of the trait anger scale was observed among the Yemeni (Cronbach's alpha $=0.76$ ) and Tunisian (Cronbach's alpha $=0.86$ ) samples. The parallel analysis suggested a three-factor solution for the anger expression scale (anger in, anger out and anger control), in accordance with the original STAXI. The internal consistency of anger in, anger out and anger control factors ranged between $0.51-0.79$ in the Yemeni sample and 0.66-0.81 in the Tunisian sample. Overall, items loaded on the anger control factor included all items proposed by the original authors and this factor had higher reliability than the other two factors in both samples. Conclusion: The results of the current study provide initial support for the use of the trait anger and anger expression scales of the STAXI in Arabic-speaking countries.

Keywords: Psychometrics; Anger; Reliability and Validity; Translations; Yemen; Tunisia.

الملخص: أهداف: تهدف هذه الدراسة إلى فحص الخصائص السيكومترية للنسخة العربية من مقياس سمة الغضب و التعبير عن الغضب

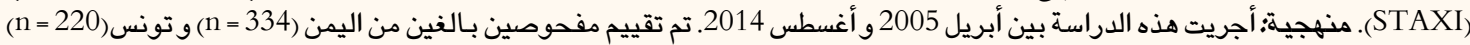

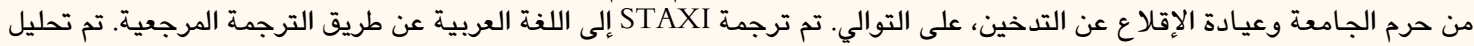

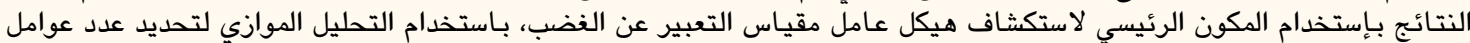

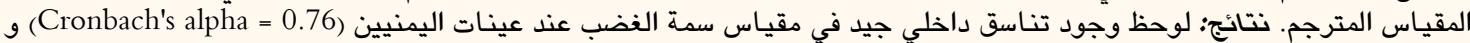

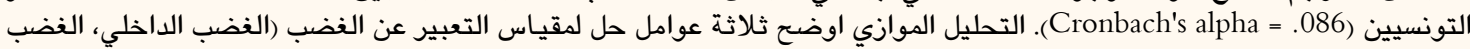

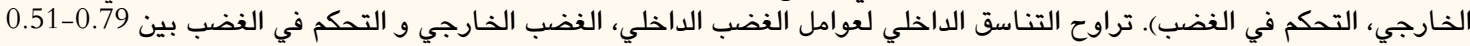

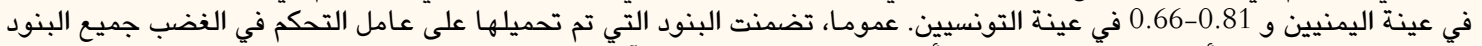

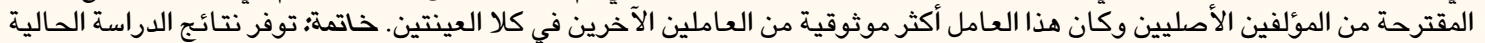

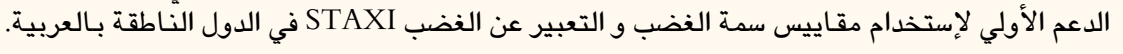

كلمات مفتاحية: سيكومترية؛ الغضب؛ الموثوقية والمصداقية؛ الترجمة؛ اليمن؛ تونس

\footnotetext{
Advances in KNOWLedge

Validated instruments to assess trait anger levels are helpful in elucidating the relationship between anger and various negative health outcomes, such as cardiovascular diseases.

To date, most research on anger and anger expression has been conducted in Western countries. There has been no attempt to validate a tool to assess anger in Arabic-speaking countries. To the best of the authors' knowledge, this study is the first to test the psychometric properties of an Arabic version of the State-Trait Anger Expression Inventory (STAXI). As the current study was conducted in two Arabic-speaking countries, the results provide initial support for the usefulness of the STAXI in this region of the world.

application to Patient Care

Anger is a commonly expressed emotion that plays an important role in physical and mental health. Research to elucidate individual differences in anger expression therefore has clinical implications for patient care, as well as potentially improving patient-provider relationships and affecting the quality of treatment programmes.
} 
A NGER IS A COMMON EMOTIONAL STATE that becomes more pronounced in stressful circumstances. ${ }^{1} \quad$ Anger expression has been associated with numerous physical and mental negative health outcomes, including cardiovascular mortality and morbidity. ${ }^{2-8}$ Valid assessments of anger therefore have an important impact on research related to health and psychological well-being. The StateTrait Anger Expression Inventory (STAXI) is one of the most frequently used instruments to assess anger and anger expression. ${ }^{9}$ Several studies have shown the sound psychometric properties of the STAXI in various populations. ${ }^{10-14}$

However, to the best of the authors' knowledge, no study has yet examined the validity of utilising the STAXI in Arabic-speaking countries. The current study was therefore designed to develop and assess the properties of an Arabic version of the trait anger and anger expression scales of the STAXI. To enhance the generalisability of the findings, samples from Tunisia in North Africa and Yemen in the Middle East were included.

\section{Methods}

This study was conducted between April 2005 and August 2014 among adults living in Yemen and Tunisia. A total of 334 male and female participants were recruited between April 2005 and March 2010 from Taiz University, Taiz, Yemen, and Sana'a University, Sana'a, Yemen, by posting flyers around the campuses and within communities. Participants were included in the study if they were not currently taking any prescribed medications and had completed their high school education. Individuals were contacted by trained research staff and were scheduled for a laboratory appointment. Additionally, 200 male smokers who visited the smoking cessation clinic at the Monastir University Hospital, Monastir, Tunisia, were recruited between February and August 2014. Potential participants were briefed regarding the objectives of the study and asked if they were interested in participating. Smokers who were over 15 years old, interested in smoking cessation and who did not have current depression were considered eligible for this study. Participants from both Yemen and Tunisia were requested to complete a series of questions which included demographic information and items from the STAXI. ${ }^{9}$ All data were collected during face-toface interviews.

The STAXI contains 44 items measuring state anger (10 items), trait anger (10 items) and three anger expression factors: anger in (AI; eight items), anger out (AO; eight items) and anger control (AC; eight items). ${ }^{9}$
These scales assess how individuals generally react or behave when they feel angry: trait anger measures how prone individuals are to experiencing anger, while AI assesses how frequently an individual suppresses their anger, $\mathrm{AO}$ gauges how often an individual expresses their anger towards other people and $\mathrm{AC}$ determines how often an individual tries to regulate their anger. A general index of anger expression can also be calculated from anger expression factors (i.e. AI plus $\mathrm{AO}$ minus AC plus 16). ${ }^{9}$ In this study, only trait anger and anger expression items of the STAXI were included since the primary purpose was to explore dimensions of habitual anger dispositions in a new population. Furthermore, although a newer version of the inventory is available $\left(\right.$ STAXI-2 $\left.{ }^{\mathrm{TM}}\right)$, the original version was used due to its established validity and reliability across different populations. ${ }^{14-19}$ For the original English version of the STAXI, internal consistency has been reported as 0.82 and 0.83 for trait anger, 0.73 and 0.74 for $\mathrm{AI}, 0.75$ and 0.77 for $\mathrm{AO}$ and 0.85 and 0.84 for $\mathrm{AC}$ among male and female college students, respectively. ${ }^{9}$ For the purposes of the current study, the STAXI was first translated into Arabic and then back-translated into English by two independent translators. In cases of discrepancy between the translations, the translators discussed the respective items until they agreed on one version.

As no data yet exist to determine the consistency of underlying dimensions of the STAXI across different cultures-and, more specifically, no studies testing anger constructs among individuals in Arabicspeaking countries-an exploratory, rather than confirmatory, data analysis method was deemed appropriate. In order to determine the appropriate number of components/factors to be retained, a parallel analysis was conducted using RanEigen software. ${ }^{20,21} \mathrm{~A}$ number of correlation matrices were constructed based on random data but with the same sample size and number of variables relative to those from empirical data. Eigenvalues obtained from the empirical dataset were then compared to those obtained from the random dataset. The number of retained components was then restricted to those which showed eigenvalues above what was expected by a principal component analysis based on random data generated by Monte Carlo methods. ${ }^{22} \mathrm{~A}$ varimax rotation was used and the Kaiser-Meyer-Olkin (KMO) index was calculated to test the adequacy of the sampling. A factor loading of 0.30 or above was employed as an a priori criterion for an item to be included in a factor. Cronbach's alpha was obtained to test internal consistency. As only the Yemeni sample included both male and female participants, a one-way analysis of variance was conducted in this sample to examine gender differences in trait anger and anger 
Table 1: Trait anger and anger expression factor scores* among adults from Yemen $(\mathrm{n}=334)$ and Tunisia $(\mathrm{n}=200)$

Factor

(n)

Trait anger

Anger in

Anger out

Anger control

Anger expression $^{\dagger}$

Men
$(\mathbf{n}=195)$
$21.9 \pm 0.4$
$17.1 \pm 0.3$
$15.6 \pm 0.3$
$21.6 \pm 0.4$
$27.1 \pm 0.6$

Mean score \pm SE
Tunisia

$\begin{array}{lccc}\begin{array}{c}\text { Yemen } \\ (\mathbf{n}=139)\end{array} & \begin{array}{c}\text { Total } \\ (\mathbf{n}=334)\end{array} & P \text { value } & \begin{array}{c}\text { Tunisia } \\ \text { Men } \\ (\mathbf{n}=\mathbf{2 0 0})\end{array} \\ 21.3 \pm 0.4 & 21.9 \pm 0.3 & 0.37 & 23.2 \pm 0.5 \\ 16.9 \pm 0.3 & 17.0 \pm 0.2 & 0.64 & 16.7 \pm 0.3 \\ 14.7 \pm 0.3 & 15.2 \pm 0.2 & 0.05 & 16.4 \pm 0.3 \\ 20.1 \pm 0.4 & 20.9 \pm 0.3 & 0.01 & 18.3 \pm 0.4 \\ 27.5 \pm 0.8 & 27.3 \pm 0.5 & 0.74 & 30.8 \pm 0.6\end{array}$

$S E=$ standard error

*Assessed using an Arabic version of the trait anger and anger expression scales of the State-Trait Anger Expression Inventory. ${ }^{\dagger}$ Calculated as anger in plus anger out minus anger control plus $16 .^{9}$

expression scales. Due to occasional missing data, variations existed between sample size and degrees of freedom for the reported variables.

This study was approved by the research and ethical committees of Sana'a University and Taiz University as well as the Monastir University Hospital in Tunisia. All subjects provided written consent before participating in the study.

\section{Results}

A total of 334 and 200 participants from Yemen and Tunisia, respectively, were included in the study. Among the Yemeni sample, 139 (42\%) were female. The mean age was $23.7 \pm 5.3$ years for men and $23.8 \pm 5.0$ years for women. All of the Tunisian participants were male, the majority (68\%) were employed and $8 \%$ were students. In the Tunisian sample, $74 \%$ had attended high school. The mean age was $42.9 \pm 14.2$ years (range: $15-75$ years old). Descriptive statistics associated with the anger scales are shown in Table 1. For both the Yemeni and Tunisian samples, the parallel analysis suggested a three-factor structure. The eigenvalues for three factors were greater for the empirical data than expected based on random data [Figure 1]. These factors were labelled according to the original three-factor solution: $\mathrm{AI}, \mathrm{AO}$ and AC. ${ }^{9}$ Factor structures of the anger expression items are described in Table 2.

For the Yemeni sample, the sample size was adequate (KMO index $=0.73$ and 0.72 for men and women, respectively). Men and women reported comparable scores on the trait anger scale (F[1,331] $=0.81 ; P=0.37)$, with an internal consistency of 0.76 ( 0.77 versus 0.74 for men and women, respectively). Item-to-total correlations ranged from 0.34-0.52. Cronbach's alpha was $0.63,0.68$ and 0.75 for the $\mathrm{AI}, \mathrm{AO}$ and $\mathrm{AC}$ factors, respectively. Men reported higher scores for $\mathrm{AO}(\mathrm{F}[1,331]=3.97 ; P<0.05)$ and $\mathrm{AC}(\mathrm{F}[1,331]=6.37 ; P<0.05)$ compared to women. Gender differences were not observed for AI or anger expression scores (Fs $<1.0 ; P>0.64$ ). The total variance accounted for by the three-factor solution was $37.6 \%$ and $36.5 \%$ in men and women, respectively. Among men, the internal consistency was 0.67, 0.63 and 0.79 for $\mathrm{AI}, \mathrm{AO}$ and $\mathrm{AC}$, respectively. Item-total correlations were between $0.28-0.46$ for AI, 0.15-0.44 for AO and 0.41-0.57 for AC. The reliability of AO improved to 0.65 when the item with the lowest itemtotal correlation was removed (item \#23). For women, internal consistency was $0.51,0.73$ and 0.68 for AI,
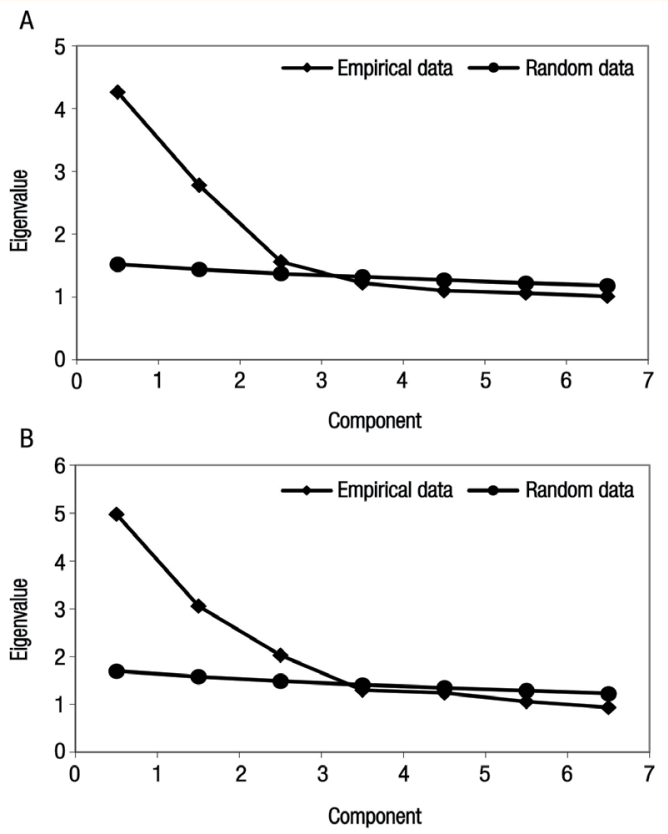

Figure 1A \& B: Parallel analyses of eigenvalues based on empirical data regarding anger expression* gathered from adults in (A) Yemen $(\mathrm{n}=334)$ and (B) Tunisia $(n=200)$ compared to eigenvalues based on random data generated by Monte Carlo methods.

*Assessed using an Arabic version of the trait anger and anger expression scales of the State-Trait Anger Expression Inventory. ${ }^{9}$ 
Table 2: Factor structure and internal consistency of anger expression factors* (anger in, anger out and anger control) among adults from Tunisia $(\mathrm{n}=200)$ and Yemen $(\mathrm{n}=334)$

\begin{tabular}{|c|c|c|c|c|c|c|c|c|c|}
\hline & \multicolumn{6}{|c|}{$\begin{array}{c}\text { Yemen } \\
(\mathrm{n}=334)\end{array}$} & \multicolumn{3}{|c|}{$\begin{array}{l}\text { Tunisia } \\
(\mathbf{n}=200)\end{array}$} \\
\hline & \multicolumn{2}{|c|}{ AI } & \multicolumn{2}{|c|}{$\mathrm{AO}$} & \multicolumn{2}{|c|}{ AC } & \multirow{2}{*}{ AI } & \multirow{2}{*}{$\mathrm{AO}$} & \multirow{2}{*}{$\mathrm{AC}$} \\
\hline & Men & Women & Men & Women & Men & Women & & & \\
\hline Variance in \% & 6.3 & 6.9 & 13.0 & 10.5 & 18.2 & 19.0 & 10.5 & 15.9 & 15.6 \\
\hline Eigenvalue & 1.52 & 1.67 & 3.13 & 2.53 & 4.37 & 4.57 & 2.02 & 4.98 & 3.06 \\
\hline Original scale Cronbach's alpha ${ }^{8}$ & 0.67 & 0.51 & 0.63 & 0.73 & 0.79 & 0.68 & 0.66 & 0.69 & 0.81 \\
\hline Current scale Cronbach's alpha & 0.68 & 0.51 & 0.73 & 0.53 & 0.66 & 0.57 & 0.59 & 0.70 & 0.70 \\
\hline \multicolumn{10}{|l|}{ Item } \\
\hline 3. Keeps things in & $0.62^{+}$ & $0.33^{\dagger}$ & - & $-0.30^{\S}$ & $0.31^{\S}$ & $0.38^{\S}$ & $0.61^{\dagger}$ & - & - \\
\hline 5. Pouts or sulks & $0.26^{\ddagger}$ & $0.41^{+}$ & $0.57^{\S}$ & - & $-0.32^{\mathbb{\$}}$ & $-0.45^{\S}$ & $0.37^{\dagger}$ & $0.47^{\S}$ & - \\
\hline 6. Withdraws & $0.41^{+}$ & $0.50^{\dagger}$ & $0.36^{\S}$ & - & - & $-0.30^{\S}$ & $0.61^{\dagger}$ & - & - \\
\hline 10. Boils inside & $0.75^{\dagger}$ & $0.53^{+}$ & - & $-0.32^{\S}$ & - & $0.35^{\S}$ & $0.70^{+}$ & - & - \\
\hline 13. Harbours grudges & $0.48^{\dagger}$ & $0.44^{+}$ & - & - & - & - & $0.58^{\dagger}$ & - & - \\
\hline 16. Secretly critical & $0.21^{\ddagger}$ & $0.52^{\dagger}$ & $0.47^{\S}$ & - & - & - & $0.40^{\dagger}$ & $0.38^{\S}$ & - \\
\hline 17. Angrier than admits & $0.53^{+}$ & $0.56^{\dagger}$ & $0.30^{\S}$ & - & - & - & $0.12 \neq$ & $0.72^{\S}$ & - \\
\hline 21. Irritated & $0.61^{\dagger}$ & $0.36^{\dagger}$ & - & $0.43^{\S}$ & - & - & $0.32^{\dagger}$ & $0.45^{\S}$ & - \\
\hline 2. Expresses anger & - & - & $0.52^{\dagger}$ & $0.58^{\dagger}$ & - & - & - & $0.71^{\dagger}$ & - \\
\hline 7. Sarcastic & - & - & $0.53^{\dagger}$ & $0.51^{\dagger}$ & - & - & - & $0.22^{\ddagger}$ & - \\
\hline 9. Slams doors & $0.32^{\S}$ & - & $0.47^{\dagger}$ & $0.55^{\dagger}$ & - & - & - & $0.46^{\dagger}$ & - \\
\hline 12. Argues with others & - & - & $0.49^{\dagger}$ & $0.59^{\dagger}$ & - & - & - & $0.35^{\dagger}$ & $0.42^{\S}$ \\
\hline 14. Strikes out & - & - & $0.31^{\dagger}$ & $0.59^{\dagger}$ & - & - & - & $0.48^{\dagger}$ & - \\
\hline 19. Says nasty things & - & - & $0.60^{\dagger}$ & $0.64^{\dagger}$ & - & - & - & $0.73^{\dagger}$ & - \\
\hline 22. Loses temper & $0.44^{\S}$ & - & $0.38^{\dagger}$ & $0.61^{\dagger}$ & $-0.32^{\S}$ & - & - & $0.69^{\dagger}$ & $-0.34^{\S}$ \\
\hline 23. Tells feelings to others & - & - & $0.35^{\dagger}$ & $0.49^{\dagger}$ & - & - & $-0.35^{\S}$ & $0.44^{\dagger}$ & $0.32^{\S}$ \\
\hline 1. Controls temper & - & - & - & - & $0.53^{+}$ & $0.56^{\dagger}$ & - & - & $0.55^{\dagger}$ \\
\hline 4. Patient & - & - & - & - & $0.63^{+}$ & $0.68^{\dagger}$ & $0.31^{\S}$ & - & $0.53^{+}$ \\
\hline 8. Keeps cool & - & - & - & $-0.36^{\S}$ & $0.74^{+}$ & $0.53^{\dagger}$ & - & $-0.39^{\S}$ & $0.58^{\dagger}$ \\
\hline 11. Controls behaviour & - & - & - & - & $0.72^{+}$ & $0.73^{\dagger}$ & - & - & $0.66^{\dagger}$ \\
\hline 15. Prevents temper loss & - & - & - & - & $0.62^{\dagger}$ & $0.68^{\dagger}$ & - & - & $0.63^{+}$ \\
\hline 18. Calms down quickly & - & - & - & - & $0.56^{\dagger}$ & $0.39^{\dagger}$ & - & - & $0.57^{+}$ \\
\hline 20. Tolerant & - & - & - & - & $0.63^{+}$ & $0.33^{+}$ & - & - & $0.66^{+}$ \\
\hline 24. Controls anger & - & - & - & - & $0.66^{+}$ & $0.63^{\dagger}$ & - & - & $0.73^{+}$ \\
\hline
\end{tabular}

$A I=$ anger in $; O=$ anger out AC = anger control.

*Assessed using an Arabic version of the trait anger and anger expression scales of the State-Trait Anger Expression Inventory. ${ }^{\dagger}$ Factor proposed by the authors of the original scale for that specific item..$^{7}$ Items proposed by the authors of the original scale that did not reach the criteria of factor loading (0.30). ${ }^{\$}$ Items proposed by the authors of the original scale that met the criteria of factor loading $(0.30) .{ }^{9}$

$\mathrm{AO}$ and $\mathrm{AC}$, respectively. Item-total correlations were between $0.15-0.32$ for $\mathrm{AI}, 0.30-0.48$ for $\mathrm{AO}$ and
0.20-0.61 for AC. The reliability of AC increased to 0.75 when the least correlated item (item \#20) was deleted; 
however, deleting the least correlated item (item \#3) in AI did not improve the reliability of the scale. For both men and women, AI was positively correlated with $\mathrm{AO}(\mathrm{r}>0.17 ; P<0.05)$ and $\mathrm{AC}$ was inversely related to AO ( $\mathrm{r}=-0.24 ; P<0.01)$. There was no relationship between $\mathrm{AI}$ and $\mathrm{AC}(P>0.63)$. For both men and women, items loaded under the $\mathrm{AO}$ and $\mathrm{AC}$ factors included all items proposed by the original authors of the STAXI and most of them loaded uniquely on the expected component. ${ }^{9}$ In addition, three to four items loaded on these components. Internal consistency for these items was 0.73 and 0.66 among men and 0.53 and 0.57 among women for $\mathrm{AO}$ and $\mathrm{AC}$, respectively. Items loaded under the AI factor among women were identical to those from the original STAXI. ${ }^{9}$ However, the data for AI among men did not replicate those from the original STAXI; ${ }^{9}$ two expected items (items \#5 and \#16) loaded weakly under this construct. Cronbach's alpha for items that met the loading criteria was 0.68 .

For the Tunisian sample, the KMO index (0.79) indicated the adequacy of the sample size. The internal consistency for the trait anger scale was 0.86 . Item-tototal correlations ranged from 0.44-0.68. Cronbach's alpha was $0.66,0.69$ and 0.81 for $\mathrm{AI}, \mathrm{AO}$ and $\mathrm{AC}$, respectively. Item-total correlations were between 0.25-0.46 for AI, $0.19-0.60$ for AO and 0.39-0.63 for $\mathrm{AC}$. The reliability of $\mathrm{AO}$ improved to 0.70 when the item with the lowest item-total correlation was removed (item \#7). The reliability of $\mathrm{AC}$ was almost the same (0.81) when the least correlated item (item \#18) was deleted. However, deleting the least correlated item (item \#3) in AI did not improve the reliability of the scale. Moreover, AI was positively correlated with $\mathrm{AO}(\mathrm{r}=0.23 ; P<0.01)$ and $\mathrm{AC}(\mathrm{r}=$ $0.17 ; P<0.05)$. In contrast, $\mathrm{AC}$ was inversely related to $\mathrm{AO}(\mathrm{r}=-0.28 ; P<0.01)$. Items loaded under $\mathrm{AC}$ included all items proposed by the original authors of the scale and most of them loaded uniquely on the expected component. ${ }^{9}$ In addition, three items loaded under these components. Internal consistency with these items was 0.70. However, AI and AO did not replicate those from the original STAXI; ${ }^{9}$ one expected item loaded weakly under each construct (items \#17 and \#7, respectively). Cronbach's alpha for items that met the loading criteria was 0.59 for $\mathrm{AI}$ and 0.70 for AO.

\section{Discussion}

The results of the current study provide initial evidence for the use of the trait anger and anger expression scales of the STAXI among individuals of Arabicspeaking countries. Trait anger was found to have good internal consistency among both Yemeni and Tunisian samples, confirming data from the original STAXI. ${ }^{9}$ Results on anger expression items were predominantly in agreement with the original structures. ${ }^{9}$ Among both Yemeni men and women, items loaded on each component included all of those proposed by the authors of the original scale. ${ }^{9}$ Moreover, items loaded on AI among women were identical to those from the original scale. ${ }^{9}$ The internal consistency of the AC factor with original items was 0.79 in men and 0.68 in women, with Cronbach's alpha improving up to 0.75 with the removal of the least correlated item. Similar trends were observed among the sample of Tunisian male smokers: items loaded under the AC factor included all items that were proposed by the authors of the original scale and all but one item were loaded under $\mathrm{AI}$ and $\mathrm{AO}$ factors proposed by the authors of the original scale. ${ }^{9}$ The high reliability of AC $(0.81$ with the original items) among the Tunisian sample is consistent with that of the Yemeni sample, which adds strength to the generalisability of the findings and suggests the potential usefulness of AC items to assess anger in Arab individuals of both genders.

In the present study, several items which were expected to load exclusively under AI also loaded on $\mathrm{AO}$ or AC. Additionally, the inclusion of items that met the loading criteria did not improve internal consistency of these scales; this trend was observed in both samples. A similar lack of psychometric properties in AI has been reported among Hispanics, African Americans and Russians. ${ }^{11,16,18}$ Although this finding may be related to the difficulty in translating or wording certain items, it is also possible that some items are not sensitive enough to identify or differentiate underlying dimensions of anger expression. For example, items such as "keeps things in" and "pouts or sulks" (items \#3 and \#5) loaded on both AI and AC and partly on $\mathrm{AO}$ in the Yemeni sample. Items such as "pouts or sulks", "secretly critical" and "irritated" (items \#5, \#16 and \#21) loaded on AI and AC, whereas "tells feelings to others" (item \#23) loaded on all three constructs in the Tunisian sample. It is possible that these items may have been misunderstood as either the suppression or regulation of anger among Yemeni and Tunisian individuals. Unexpected loading of items such as "pouts or sulks" has been found in other studies. ${ }^{10,11,23}$ Future studies should therefore exercise caution in the interpretation or translation of these items. ${ }^{14}$

To the best of the authors' knowledge, the current study is the first to show gender differences in anger expression among Middle Eastern adults. Higher $\mathrm{AO}$, as well as lower $\mathrm{AC}$, was found in Yemeni men compared to women; however, the extent to which gender moderates anger expression is not clear. Two previous studies have reported gender differences 
in item loadings of anger expression scales. ${ }^{10,11}$ For example, certain items (i.e. "secretly critical" and "pouts or sulks") considered to be part of AI actually loaded on AO among women but not men, while another study observed that the item "I pout or sulk" loaded on both $\mathrm{AI}$ and $\mathrm{AO}$ for men only. ${ }^{10,11}$ These findings suggest the possibility that anger expression is different in men and women. Other research has shown no gender differences in anger expression among Caucasians and African Americans, although one study involving individuals from multiple ethnic backgrounds found higher $\mathrm{AC}$ and lower anger expression among women. ${ }^{8,16,19}$ Recent data suggest the role of situational determinants in gender differences in anger expression; using a domain-specific strategy, men and women were found to express anger differently in various circumstances (e.g. women were more likely to report $\mathrm{AO}$ at home than men, while men reported greater $\mathrm{AO}$ at work than women). ${ }^{24-26}$ However, this theory has not been directly tested among Arabic-speaking adults. In the current study, gender differences were noted in the internal consistency of anger expression items; in general, reliability scores for $\mathrm{AI}, \mathrm{AO}$ and $\mathrm{AC}$ were lower among women compared to men. It is possible that men and women interpreted or perceived some items differently. Future research should take into account the role of sociocultural setting on gender differences in anger expression. Fischer et al. found that women living in countries where females were more empowered to engage in economic and political life were more likely to report anger expression. ${ }^{27}$ Accounting for these factors may help improve the usefulness of the STAXI across different populations.

The results of the current study suggest that trait anger and AC scales can be used in Arabic-speaking regions; this would subsequently help to assess correlates with health and psychological risks in these countries. Haukkala et al. reported that AC levels can predict cardiovascular mortality and morbidity. ${ }^{3}$ Another study showed that smokers with high trait anger suffered from increased withdrawal symptoms during acute nicotine withdrawal and had a greater risk of relapse within a week of cessation. ${ }^{28}$ Due to the tobacco epidemic causing serious concern in many Arab countries, including Yemen and Tunisia, investigating the role of trait anger in emotion regulation and drug consumption behaviour may have important clinical implications within these populations. $^{29,30}$

The current study had several limitations; as such, these results should be considered preliminary. Future work should examine the validity of using the STAXI in larger Arabic-speaking samples. Results from Yemen and Tunisia were difficult to compare because of differences in sample characteristics, as the sample from Yemen consisted of young adult men and women whereas the sample from Tunisia included only male smokers who were seeking treatment. Furthermore, these countries have different geographical, socioeconomic and cultural influences. These might explain differences in reliability and validity in comparison to the original STAXI. ${ }^{9}$ Moreover, this study did not test the state anger scale as the purpose of this study focused on validating the trait anger and anger expression scales, which may have direct health consequences. ${ }^{3}$ Further research should examine other components of validity (e.g. concurrent or discriminant validity) and reliability (e.g. test-retest reliability) of Arabic versions of the inventory and use the latest version of the scales (STAXI- $\left.2^{\mathrm{TM}}\right) .{ }^{15}$ Despite these limitations, the study included participants from two different countries, Yemen and Tunisia, which strengthens the generalisability of the findings.

\section{Conclusion}

This study provides initial support for the structural validity and reliability of the STAXI trait anger and anger expression scales among adults in Arabicspeaking countries. The internal consistency of trait anger and $\mathrm{AC}$ items in the current study were comparable to data from the original STAXI scales. Preliminary gender differences in $\mathrm{AC}$ and $\mathrm{AO}$ suggest the role of social and cultural influences in anger expression. Accounting for these influences may help to improve the usefulness of the inventory in elucidating the relationship between anger expression and health risks in these populations.

\section{CONFLICT OF INTEREST}

The authors declare no conflicts of interest.

\section{FUNDING}

This study was supported in part by grants from the National Institutes of Health/Fogarty International Center (\#R03TW007219), the National Institute for Drug Abuse (\#DA024626) and the Office of International Programs at the University of Minnesota, Duluth, Minnesota, USA.

\section{ACKNOWLEDGEMENTS}

The authors would like to thank Dr Anisa Dokam, Dr Abed N. Kasim and Dr Mohammed Al-Soofi at the Taiz University as well as Dr Najat S. Khalil and Dr Molham Al-Habori at the Sana'a University for their efforts in developing the research programme and coordinating the study. In addition, Ms Basma 
A. Thabe and Mr Khaled Al-Sahmiry are thanked for their help with data collection and Dr Volker Hodapp is also thanked for his support with the preliminary data analysis.

\section{References}

1. Averill JR. Studies on anger and aggression: Implications for theories of emotion. Am Psychol 1983; 38:1145-60. doi: 10.1037/0003-066X.38.11.1145.

2. Everson SA, Goldberg DE, Kaplan GA, Julkunen J, Salonen JT. Anger expression and incident hypertension. Psychosom Med 1998; 60:730-5. doi: 10.1097/00006842-199811000-00014.

3. Haukkala A, Konttinen H, Laatikainen T, Kawachi I, Uutela A. Hostility, anger control, and anger expression as predictors of cardiovascular disease. Psychosom Med 2010; 72:556-62. doi: 10.1097/PSY.0b013e3181dbab87.

4. Gonzalez OI, Novaco RW, Reger MA, Gahm GA. Anger intensification with combat-related PTSD and depression comorbidity. Psychol Trauma 2016; 8:9-16. doi: 10.1037/ tra0000042.

5. Smith TW, Glazer K, Ruiz JM, Gallo LC. Hostility, anger, aggressiveness, and coronary heart disease: An interpersonal perspective on personality, emotion, and health. J Pers 2004; 72:1217-70. doi: 10.1111/j.1467-6494.2004.00296.x.

6. Deffenbacher JL, Oetting ER, Lynch RS, Morris CD. The expression of anger and its consequences. Behav Res Ther 1996; 34:575-90. doi: 10.1016/0005-7967(96)00018-6.

7. Erwin BA, Heimberg RG, Schneier FR, Liebowitz MR. Anger experience and expression in social anxiety disorder: Pretreatment profile and predictors of attrition and response to cognitive-behavioral treatment. Behav Ther 2003; 34:331-50. doi: 10.1016/S0005-7894(03)80004-7.

8. al'Absi M, Bongard S. Neuroendocrine and behavioral mechanisms mediating the relationship between anger expression and cardiovascular risk: Assessment considerations and improvements. J Behav Med 2006; 29:573-91. doi: 10.1007/ s10865-006-9077-0.

9. Spielberger CD. State-Trait Anger Expression Inventory: Professional manual. Odessa, Florida, USA: Psychological Assessment Resources, 1996.

10. Forgays DG, Forgays DK, Spielberger CD. Factor structure of the State-Trait Anger Expression Inventory. J Pers Assess 1997; 69:497-507. doi: 10.1207/s15327752jpa6903_5.

11. Reyes LR, Meininger JC, Liehr P, Chan W, Mueller WH. Anger in adolescents: Sex, ethnicity, age differences, and psychometric properties. Nurs Res 2003; 52:2-11. doi: 10.1097/00006199200301000-00002.

12. Azevedo FB, Wang YP, Goulart AC, Lotufo PA, Benseñor IM. Application of the Spielberger's State-Trait Anger Expression Inventory in clinical patients. Arq Neuropsiquiatr 2010; 68:231-4. doi: 10.1590/S0004-282X2010000200015.

13. Fuqua DR, Leonard E, Masters MA, Smith RJ, Campbell JL, Fischer PC. A structural analysis of the State-Trait Anger Expression Inventory. Educ Psychol Meas 1991; 51:439-46. doi: $10.1177 / 0013164491512018$.

14. Kassinove H, Sukhodolsky DG, Eckhardt CI, Tsytsarev SV. Development of a Russian State-Trait Anger Expression Inventory. J Clin Psychol 1997; 53:543-57. doi: 10.1002/ (SICI)1097-4679(199710)53:6<543::AID-JCLP3>3.0.CO;2-L.
15. Spielberger CD. STAXI- ${ }^{\text {in: }}$ : State-Trait Anger Expression Inventory- $2^{\mathrm{Ts}}$ - Professional manual. Odessa, Florida, USA: Psychological Assessment Resources, 1999.

16. Armstead CA, Clark R. Assessment of self-reported anger expression in pre- and early-adolescent African Americans: Psychometric considerations. J Adolesc 2002; 25:365-71. doi: 10.1006/jado.2002.0481.

17. Knight RG, Chisholm BJ, Paulin JM, Waal-Manning HJ. The Spielberger Anger Expression Scale: Some psychometric data. Br J Clin Psychol 1988; 27:279-81. doi: 10.1111/j.20448260.1988.tb00792.x

18. Eckhardt CI, Kassinove H, Tsytsarev SV, Sukhodolsky DG. A Russian version of the State-Trait Anger Expression Inventory: Preliminary data. J Pers Assess 1995; 64:440-55. doi: 10.1207/ s15327752jpa6403_4

19. Musante L, Treiber FA, Davis HC, Waller JL, Thompson WO. Assessment of self-reported anger expression in youth. Assessment 1999; 6:225-34. doi: 10.1177/107319119900600303.

20. Lautenschlager GJ. A comparison of alternatives to conducting Monte Carlo analyses for determining parallel analysis criteria. Multivariate Behav Res 1989; 24:365-95. doi: 10.1207/ s15327906mbr2403_6.

21. Enzmann D. RanEigen: A program to determine the parallel analysis criterion for the number of principal components. Appl Psychol Meas 1997; 21:232. doi: 10.1177/01466216970213003.

22. Hayton JC, Allen DG, Scarpello V. Factor retention decisions in exploratory factor analysis: A tutorial on parallel analysis. Organ Res Methods 2004; 7:191-205. doi: 10.1177/109442810 4263675.

23. Lievaart M, Franken IH, Hovens JE. Anger assessment in clinical and nonclinical populations: Further validation of the State-Trait Anger Expression Inventory-2. J Clin Psychol 2016; 72:263-78. doi: 10.1002/jclp.22253.

24. Bongard S, Martin NM, Seip M, al'Absi M. Evaluation of a domain-specific anger expression assessment strategy. J Pers Assess 2011; 93:56-61. doi: 10.1080/00223891.2010.513705.

25. Bongard S, al'Absi M. Domain-specific anger expression and blood pressure in an occupational setting. J Psychosom Res 2005; 58:43-9. doi: 10.1016/j.jpsychores.2004.04.370.

26. Bongard S, al'Absi M. Domain-specific anger expression assessment and blood pressure during rest and acute stress. Pers Individ Dif 2003; 34:1383-402. doi: 10.1016/s01918869(02)00106-x.

27. Fischer $\mathrm{AH}$, Rodriguez Mosquera $\mathrm{PM}$, van Vianen $\mathrm{AE}$, Manstead AS. Gender and culture differences in emotion. Emotion 2004; 4:87-94. doi: 10.1037/1528-3542.4.1.87.

28. al'Absi M, Carr SB, Bongard S. Anger and psychobiological changes during smoking abstinence and in response to acute stress: Prediction of smoking relapse. Int J Psychophysiol 2007; 66:109-15. doi: 10.1016/j.ijpsycho.2007.03.016.

29. al'Absi M, Grabowski J. Concurrent use of tobacco and khat: Added burden on chronic disease epidemic. Addiction 2012; 107:451-2. doi: 10.1111/j.1360-0443.2011.03684.x.

30. Fakhfakh R, Hsairi M, Maalej M, Achour N, Nacef T. Tobacco use in Tunisia: Behaviour and awareness. Bull World Health Organ 2002; 80:350-6. doi: 10.1590/S0042-96862002000500004. 